\title{
THE (SHE) WOLF OF WALL STREET
}

\author{
Corina Sheerin \\ School of Business, National College of Ireland, Dublin 1
}

\begin{abstract}
$\mathrm{T}$ he recent release of the Wolf of Wall Street movie has reignited interest in the extreme lifestyle and behaviours of Wall Street executives. The movie portrays life in 'front office' investment management as one characterised by excess, and those who succeed in the sector as assertive, driven individuals who all happen to be male. Using the lens of gender, this research examines, within an Irish context, what perceptions and beliefs are held among potential entrants to the sector regarding the personality traits necessary to survive and succeed. Subsequently, the influence, if any, of experience of working in the sector is explored for both men and women. The research makes an important contribution to existing literature by exploring whether the 'wolfish' characteristics deemed essential for survival in the hegemonic-masculine investment management environment have led women to believe they will never fit within this culture and as such opt out. Findings indicated that gender differences were apparent among potential entrants to the sector with women ranking assertiveness, confidence and the ability to network more highly than their male peers. Experience of working in the sector did not affect the views of women. For men working in the sector, less importance was placed on factors such as confidence, personal initiative and communication skills when compared with male peers with no experience.
\end{abstract}

\section{INTRODUCTION}

One of the most striking features of third-level education and the global labour market is that despite improvement in the numerical presence of women, significant differences exist in the fields of study and occupations of men and women (Weisgram, Bigler and Liben, 2010). In particular, women are significantly 
Sheerin

under-represented in fields such as construction, engineering and computer science in both the classroom and the workplace. A significant body of literature has examined women's perceptions and experiences in these domains (Rosenbloom, Ash, Dupont and Coder, 2008; Hegewisch, Liepmann, Hayes and Hartmann, 2010; Johnson, 2013). Within the field of finance, women are statistically well represented in an Irish context. In 2010, 56 per cent of all those undertaking third-level undergraduate finance programmes ${ }^{1}$ were male while 44 per cent were female. Statistics for 2009 and 2008 showed a relatively even gender breakdown also ${ }^{2}$ (Higher Education Authority, 2013). At postgraduate level, however, divergence between the genders undertaking programmes in finance is evident. Men outnumbered women in 2010 by a ratio of 2:1, clearly indicating that women are leaking from the education pipeline (Higher Education Authority, 2013). In 2009, 432 students undertook postgraduate study in finance; 86 per cent of these were male $(n=371)$ compared with only 14 per cent female ( $\mathrm{n}=61$ ) (Higher Education Authority, 2013).

In the labour market, women are well represented with almost 60 per cent of all employees globally in the financial services sector female. Despite women being well represented within the sector overall, there persists a dearth of women in management roles and a notable absence of women in the subsector of investment management. A mere 19 per cent of women working in the financial services sector progress to leadership or senior roles and only 2 per cent to chief executive officer (CEO) positions (PricewaterhouseCoopers, 2013, p. 1). The absence of women in investment management is most acute within fund management and trading roles (the most lucrative roles within the sector). According to Riach and Cutcher (2014) and Lewis (1989, p. 9), here 'a jungle of chest-pounding males' prevails.

'Financial services' is an overarching term, which is typically used to describe three primary business functions, namely banking and capital markets, investment management, and insurance (Forfás, 2007). Over the last decade, some literature concerning women's experience of working in financial services sectors such as insurance and retail banking has emerged in a global context (Burgess, 2003; Ozbilgin and Woodward, 2004; Ogden, McTavish and McKean, 2006; Broadbridge, Maxwell and Ogden, 2007). Within an Irish context, research concerning women's representation, experience and perceptions of financial services is somewhat limited. For the most part, research of this nature has focused on women in the related domains of accounting and, to a lesser extent, auditing and taxation (Barker and Monks, 1998; Twomey, Linehan and Walsh, 2002). The common theme within the existing research is the under-representation of women at senior management levels in their professions.

To date, the subsector of investment management has been relatively underresearched in academic literature (McDowell, 1997; Rowe and Crafford, 2003; Roth, 2006; McDowell, 2010; Pryce and Sealy, 2013). Albeit a sector under-researched in academia, over the last number of years sector-specific gender-related issues have received widespread coverage in the media, with a number of whistleblowers sharing their experience of working lives in the sector (Anderson, 2009; Suzana, 2009; Thompson, 2010).

'Investment management' is a term that is widely used in both the media and within the financial services sector. Despite the ubiquitous nature of the term, it does 
not have clearly defined parameters and is sometimes referred to as 'investment banking' or 'portfolio management'. For the purpose of this study, the investment management sector is classified by the parameters set down by Forfás (2007) whereby the sector is comprised of two sub-groups of employment, referred to commonly as 'front office' (investment management) and 'back office' (fund servicing).

Generally, 'front office' refers to those working in roles such as trading and positions related to the management of funds. The required employment profile for these roles is personnel with high levels of quantitative and mathematical skills. Almost all candidates working in investment management would, at a minimum, hold a postgraduate degree in finance or a related discipline or a professional qualification such as the Chartered Financial Analyst (CFA) qualification. Within the Irish market, front office positions are scarce and commonly seen as high-value, well-paid and knowledge-intensive roles (Forfás, 2007). 'Front office' investment management is often simply referred to as 'investment management', and this convention will be adopted for the remainder of this paper.

While there are no global statistics concerning the gender composition of the investment management sector, it is widely accepted that front office roles are where 'men form the majority' and 'the old boys' club seems to have become an accepted norm' (Rowe and Crafford, 2003, p. 24). The typical environment is one where 'hundreds of men in smart navy blue suits stand around shouting at each other. Nearly all of them are white and most under forty' (Anderson, 2009, p. 20). On the trading floor this is even more prevalent and 'one woman for every hundred men' is not uncommon (Lynn, 2005, p. 45).

The question of why women are absent from front office roles in the sector is a relatively under-researched one. The most common reason proposed in the literature is that women simply are not the right 'fit' for the sector (Pryce and Sealy, 2013, p. 461). The culture of investment management is accepted as one that is dynamic and cut-throat in nature and is dominated by driven, confident, assertive individuals whose key objective is profit-making at all costs (McDowell, 1997; Rowe and Crafford, 2003; Roth, 2006). This is a perspective further embedded by the media and movies like The Wolf of Wall Street. In their study of UK investment managers, Pryce and Sealy (2013, p. 450) indicated that the macho and aggressive environment of investment management glorifies the individualistic pursuit of financial gain at all cost'. According to Jones (1998) and McDowell (1997), women, when compared with men, are often overtly or covertly excluded from front office roles in investment management. This is primarily a consequence of the entrenched perceptions and beliefs widespread within the sector and further perpetrated by the media that women do not have the right personality traits to fit within the male-dominated culture of the sector (Estes and Hosseini, 1988; North-Samardzic and Taksa, 2011; Wilson, 2012). These exclusion tactics also have the effect of discouraging potential female entrants into the sector and as such may explain why women are leaking from the postgraduate pipeline in finance.

Holland (1996, p. 367) argued that 'people flourish in their work environment when there is a good fit between their personality type and the characteristics of the environment'. This research aims to identify what expectations and beliefs are held amongst the potential entrants, namely postgraduate students, regarding the 
Sheerin

personality traits considered necessary to fit within front office investment management roles. In particular, this paper focuses on whether a gender difference exists among the expectations of men and women regarding traits necessary for survival in the sector. Finally, whether experience has an influence on the perspectives of men and women was explored. Examining the views of postgraduate students both with and without experience of working in investment management allowed for analysis of whether the beliefs of women and men differed as experience of the sector was gained. Examining these questions allows us to consider whether the Irish investment management sector is similar to other environments and whether women are opting out of investment management front office roles because of the hegemonic, masculine environment as depicted in The Wolf of Wall Street and the consequential belief that they will never fit within this culture.

Rees (2005, p. 567) claims that it is vital that companies and institutions understand the 'business case' for gender equality and appreciate how a more gender-equal team contributes to the bottom line. This is an issue that is becoming critical to policymakers across many different occupations, but in particular within male-dominated fields of study and work. This study makes a very valuable contribution in addressing this question within the field of investment management. Most recently, the Horizon 2020 European Union research on gender equality within science highlighted concerns about the need for gender balance within science and its importance in overall organisational performance (Lichten, 2013). In order to achieve the objective of gender equality, understanding the expectations and perceptions of potential entrants, and in particular female potential entrants, concerning life in the sector is essential.

Within an Irish context, this is the first study to focus on perceptions and beliefs about the traits necessary for survival and success within investment management and as such makes an important contribution to existing literature. Equally, this research has strength in addressing the perceptions of both potential entrants and those already working in the sector. Addressing whether men and women differ in their beliefs about life in the sector as well as identifying whether those 'wolfish' traits as portrayed in the media are in fact barriers to women is essential in redressing the gender imbalance currently evident in the fund management suite and trading floors of front office.

The research strategy involved a mixed-method approach using focus groups as well as a questionnaire survey, underpinned by a pragmatist philosophical stance. Adopting this approach allowed for a more holistic understanding of relevant ideologies and practices to explain the factors that contribute to survival and success within the sector. Equally, mixing methods allowed for 'complementarity' of results as well as 'expansion' of the breadth and extent of the inquiry (Greene, Caracelli and Graham, 1989, p. 259).

The remainder of the paper is organised as follows. At the outset, the context for the research question under examination, which is cross-disciplinary in nature and draws upon the fields of organisational behaviour, economics, finance and sociology, is set out. A summary and critique of pertinent literature that describes the factors underpinning occupational choice, as well as the investment management working environment and the commonly held perceptions concerning the sector, 
is presented. Understanding the culture and organisational context underpins an understanding of what personal characteristics individuals in the sector of work deem essential in order to fit in, survive and ultimately succeed. A quantitative comparative analysis of the views of men and women concerning ten personality traits deemed essential for success is explored based on the findings of the survey. The paper concludes with an examination of the implications of the findings.

\section{LITERATURE REVIEW}

\section{The Career-Testing Ground}

Within the fields of sociology and organisational behaviour there is an acceptance concerning the complex relationships that exist between the individual and society and in particular individuals and the occupations they choose, as well as the organisations they work in. Adya and Kaiser (2005) and Adya (2008) claim that the choice to seek careers in male-dominated sectors like investment management is hugely affected by socially constructed perceptions of the sector and expectations of life within. Morgan, Gelbgiser and Weeden (2013) and Hakim (2002) argue that social stereotypes concerning the role of women in society and in particular within certain sectors of work cause women to start developing attitudes towards certain careers and occupations at an early age. Watt (2010) concluded that personality traits and individual-led factors such as self-efficacy, expectations of success and motivations, along with socio-cultural factors, underlay the career choices of women, particularly in male-dominated fields. Eccles (1994), in her model of educational and occupational choice (titled the Model of Achievement Related Choices), propounded that a range of psychological and social factors influence educational and occupational choice, with the primary concern being expectations of success borne of personality fit.

Expectations concerning occupations and/or working life in certain sectors are often shaped by parents, peers, teachers and media influence as well as environmental and cultural factors (Eccles, 1994; Bandura, Barbaranelli, Caprara and Pastorelli, 2001; Schoon and Parsons, 2002; Brown, 2004; Adeyemo, 2005; Mello, 2008; Ham, Junankar and Wells, 2009; Eccles, 2009). However, the reoccurring theme across the literature concerning educational and occupational choice relates to the influence of personality and whether one has the traits considered necessary for success in certain careers. Larson, Rottinghaus and Borgen (2002) and Ham et al. (2009) argue that the decision to choose a particular career path is intrinsically linked to the personal characteristics of an individual.

In recent years, a growing body of literature has emerged that draws upon psychological theories to explain occupational choice. The overarching message from this literature is the strong correlation between gender, personality type and occupational choice (Heckman, Stixrud and Urzua, 2006; Borghans, Duckworth, Heckman and ter Weel, 2008; Furnham and Fudge, 2008). Cobb-Clark and Tan (2009) argue that occupational choice depends on personality, which is highly correlated with gender. Wigfield, Battle, Keller and Eccles (2002) claimed that gender difference exists in relation to goal-setting, attitudes towards careers and beliefs about selfachievement, and this contributes to the existence of gender inequalities within the 
Sheerin

labour market. Heckman et al. (2006) go so far as to claim that personality has a greater effect on occupational choice than cognitive ability.

While no study has examined occupational choice within finance specifically, the fusion of economic and psychology theories has revolutionised and enhanced consideration of educational and occupational choice across all occupations. In the case of investment management, a small but emerging body of literature is evident concerning various aspects of the sector including culture and gender discrimination (McDowell, 1997; Jones, 1998; Poggio, 2000; Rowe and Crafford, 2003; Roth, 2006; McDowell, 2010; Pryce and Sealy, 2013). A number of biographies have also been authored by men and women concerning life in the investment management sector, and most notably its prevailing culture and norms (Lynn, 2005; Anderson, 2009; Thompson, 2010).

The emergent theme from the academic literature and biographies alike relates to the culture of the sector that is characterised by a male-dominated environment where one must adopt a certain personality type and ultimately subscribe to the 'boys' club' mentality to fit in and succeed. In order to examine whether a gender difference exists among potential entrants concerning expectations of life in the sector, and the necessary personality traits deemed essential for survival, a comprehensive exploration of the overarching organisational culture including its embedded rituals, processes and behaviours is warranted.

\section{Investment Management - Perceptions and Realities of Life on the Inside}

\section{Networking}

When examining the perceptions of potential female entrants as well as the experiences of women working in male-dominated sectors, networking skills, being a team player and communicating effectively are seen as essential for success (Thompson, 2010; Anderson, 2009). Within the domain of accounting in Ireland, Barker and Monks (1998, p. 816) uncovered the fact that effective networking is essential for success; however 'women appear to lack the support networks which men have developed over the years'. This is despite the fact that 'no differences in the ambitions of male and female accountants' were found in their research. Within investment management, beliefs concerning the prevalence of the old boys' network and lack of support for women in accessing networks is even more acute (McDowell, 1997, 2010; Jones, 1998; Lynn, 2005; Thompson, 2010; Moya, 2011). Within the front office 'men form the majority' and 'the old boys' club seems to have become an accepted norm' (Rowe and Crafford, 2003, p. 24).

In particular, the 'old boys' network' was seen at its most evident on the trading floor (Long, 2009, p. 23). Thompson (2010, p. 54) concurred, highlighting that the 'broking floor is arguably the most aggressive, male dominated environment that anyone could work in' and as such difficult for women to access. Jones (1998), in his United Kingdom (UK)-based study, along with Moya (2011), in a United States (US) context, agreed and argued that the masculine culture is continuously being reinforced through both image and the recruitment processes. Moya (2011) indicated that for most potential entrants or those seeking promotion, there is an unspoken understanding that 'men who have traditionally dominated Wall Street and the City 
of London tend to appoint and promote people like themselves. People are very comfortable with people who are like them. Being a female in a male-dominated world can make it difficult.' Roth (2006, p. 73), within a US context, similarly found that 'the culture of machismo and fraternity-like environments is the stuff of Wall Street lore'. Ely (1995) and Lockwood (2006) argue that for women considering a career or working within male-dominated occupations, there is a heightened perception of behavioural and psychological differences between the genders and, as such, the issue of 'fit' remains a concern.

\section{Assertiveness, Confidence, Personal Initiative and Leadership}

Rowe and Crafford (2003), Roth (2006), Anderson (2009) and Thompson (2010) agreed that 'in addition to the male domination of the industry, there appears to be a typical character suited to Investment Banking' (Rowe and Crafford, 2003, p. 23). They described this typical character as an assertive, confident leader who thrives on personal achievement. Anderson (2009) in particular highlighted the importance of confidence and personal initiative in selling oneself - personality traits he claimed were more readily associated with men. Estes and Hosseini (1988) proposed that women are often less confident than men in their own decision-making abilities and, as such, are not hired in equal numbers to men in investment management roles. Such a lack of confidence is sometimes perceived as inability or 'lacking the killer instinct' (Wilson, 2012). Wilson goes on to argue that so few women reach the top in banking, finance and journalism because they are perceived as not having what it takes, while 'men who reach the top have usually done so possessing a steely ruthlessness and single-mindedness which is ... let us be honest ... is a masculine quality' (Wilson, 2012).

\section{Problem-Solving and Communication Skills}

According to Pryce and Sealy (2013, p. 450), individuals who are problem-solvers and who 'show initiative, [and are] proactive' will survive the investment management sector. According to McDowell (2010), such troubleshooting skills, along with the necessary numerate ability needed for front office roles, are more likely to be found among male recruits. Anderson (2009) argued that while being numerate and technically adept was important, ambition far outweighed in terms of importance. He indicated that despite having interviewed several exceptionally academically gifted individuals, both male and female, the new recruits to front office were always a certain type - they 'generally ticked all the stereotypical boxes: ambitious, white, male, heterosexual Oxbridge graduates' (Anderson, 2009, p. 352).

Davies (2012), a former UK investment banker, claimed that the ability to confidently communicate was the most important attribute for front office employees. She argued that 'it doesn't always matter what you say as long as you deliver it with supreme confidence'. Effective and persuasive communication is an essential skill set in any occupation within male-dominated fields of work and study. When examining communication and language through the lens of gender, it is evident that men and women communicate very differently. Women are seen to 'value talk for the relationships it creates' (Merchant, 2012, p. 19) and as such are often cited as better communicators than men. Within investment management, female 
Sheerin

communication styles that are orientated towards creating relationships are not always favoured. Instead a more male-orientated communication style, whereby men perceive the world they engage in as a 'hierarchical social order' (Tannen, 1990, p. 361), and communication as a means to advance, is preferable. According to Merchant (2012, p. 19), men see conversation as an opportunity to 'enhance social dominance', achieve goals and maintain an elevated status rather than engage in communal orientations, all of which fits within the performance-driven environment of investment management.

\section{The Working Environment}

One of the traits most emphasised in the literature as essential for survival in investment management is the ability to function effectively within the pressurised performance-led working environment. According to Roth (2003, p. 788), 'Wall Street is driven by compensation as a measure of success'. Hewlett and Luce (2006, p. 53) concurred, indicating that performance drives the sector and the 'extreme work ethos' is common. According to Lewis (1989), a certain type of employee was necessary for investment management. Such employees 'gave themselves entirely over to their employers and worked around the clock' - such individuals were identified as 'good employees'. They were usually male, unmarried, with no commitments: 'rarely they slept, the more they looked ill [and] the nearer they appeared to death the better they appeared at their job' (Lewis, 1989, p. 41).

McDowell (2010, p. 654) proposed that investment management is aggressive in nature. She further argues that on the trading floor particularly 'an aggressive, hetero-sexualized masculine confidence in men's own abilities creates an atmosphere inimical to many women, and to homosexual men'. Turco (2010, p. 903) agreed, describing the sector as 'macho, aggressive', 'intense and ruthless'. Jones (1989) argued that as a consequence of the inherent performance-driven working environment, it is supposed therefore that only those individuals with a high level of objectivity and a detached personality can survive the pressure. Rowe and Crafford (2003, p. 24) similarly concluded that the 'right fit' for investment management were individuals who were motivated by personal performance - 'an obsessive type of character'. They claimed that 'men tend to be more focused on one obsessive thing which fits with the industry as opposed to women who generally have a range of interests'.

Anderson (2009, p. 29), drawing upon his own experience in the sector, indicated that in the graduate recruitment phase he understood very quickly that 'playground banter is one of the most important skills in Investment Banking'. He noted that, demonstrating the ability 'for taking the piss and not flapping when having the piss taken out of me ... were more important than diligence or analytical ability in gaining the respect of the trading floor' (Anderson, 2009, p. 29). Thompson (2010) similarly described the importance of having the right personality to be part of the 'club' in order to survive the sector. She experienced the sector as one where women were seen as the outsiders, and this was particularly an issue for mothers who were balancing work and home.

Morgan et al. (2013) highlighted that women consider the issue of work-life balance when selecting and eliminating certain career paths and this commences at the 
outset of their careers. They indicated that young women both expect and anticipate the conflict between work and home life long before they experience it, and as such opt out of careers considered incompatible with family life, such as investment management. Thompson (2010), in her own biography of life as a trader, highlighted the lack of work-life balance. She also drew attention to the homosocial behaviour that was part of the fibre of the sector. She recalls how she anticipated such an environment but not to the degree that she experienced. She highlighted how she was nicknamed 'airbags' by her colleagues and this was positioned as a term of endearment (Thompson, 2010, p. 51). McDowell (1997) also referred to the sexualised language used to objectify women. She indicated that women anticipated such behaviour and were routinely referred to as "skirts", "slags", "brasses" and "tarts", all synonyms for "prostitutes"' (McDowell, 1997, p. 141). Anderson (2009, p. 9), however, indicated that such comments were not limited to women and such behaviour was simply part of the culture of the sector and to be expected. Profits and performance were the driving force and inappropriate behaviour and language were accepted as a part of the landscape. Human resource training and policies to address this behaviour were, at best, ignored. The pertinent view was that to survive the sector a 'thick skin' personality type was a prerequisite.

In order to achieve success in certain roles within investment management, client entertainment was deemed essential. Like many other aspects of the culture, it is highly saturated with masculine traits. Strip clubs were seen as a common form of entertainment to 'conduct business meetings', according to Thompson (2010, p. 53), and this is a fact that is further highlighted by the media. Hargreaves (2008) concurred and claimed a 'lap dance ethos' remains at the heart of the Square Mile and this often discourages young women from even considering a career in the sector. Anderson (2009, p. 57) claimed that 'the macho City culture made it difficult to relate to women' and if women want to gain entry they have to present and engage like 'one of the boys'. Sport was also seen as an integral aspect of client entertaining and almost always the sporting event 'revolved around men's sports and men's activities' (Roth, 2006, p. 85). Roth (2006, p. 85) further claimed that such an environment 'really impacted [women's] ability to develop relationships with people'.

Maddock and Parkin (1993) labelled such performance-focused environments as cultures of 'smart machos' where managers were all-consumed by a pressure to perform and did whatever was necessary to advance their careers. According to Davidson and Burke (1994, p. 30), employers who facilitate "the "smart macho culture" have no desire to block employees who can work eighty hours a week and deliver on time'. Maddock and Parkin (1993) and Davidson and Burke (1994) claimed that such employees were usually presented as single and male.

The working environment of investment management and the difficulties women face in breaking into this male-dominated field concurs with the evidence from other disciplines including science, healthcare and academia. Kemelgor and Etzkowitz (2001, p. 240), in their study of women in science, indicated that women faced both the real and perceived old boys' network of obstacles on a daily basis and in particular the practices of 'ongoing subtle and overt exclusion'. They claimed that 'two worlds' (Kemelgor and Etzkowitz, 2001, p. 242) were in place, one for each gender. Rhoton (2011) argued that for many women the choice of opting into 
Sheerin

work within a male-dominated environment implies ignoring gender differences and accepting certain masculine behaviours as normal professional practices, leading women to feel it necessary to exhibit characteristics of aggression, ambition, etc. in order to fit in. Bevan and Learmonth (2013) indicated that subtle discrimination was commonly experienced by women in healthcare science and, not unlike investment management, very often it was not highlighted or discussed by women as they had anticipated it and now, once inside the sector, accepted it as the industry norm. Most women in investment management, much like healthcare, 'accept' the fact that the decision to 'become one of the boys' and enter 'the club' brings with it barriers, hurdles and blocks. Bevan and Learmonth (2013, pp. 137-138) highlight that women have indicated that they are aware of the difficulties that lie ahead but they 'had no language through which to question and oppose - or even fully articulate - these difficulties'. Sonnert and Holton (1995) and Valian (2005) drew similar conclusions within the domains of academia and science.

\section{Path to Success}

In order to gain entry, endure and succeed in investment management, the key factor emanating from the literature is the need to fit into the male-dominated, performance-orientated nature of the sector. McDowell (1997, p. 130) referenced the importance of 'flexibility, team spirit and an ability to fit in' in order to succeed within investment management. According to Anderson (2009, p. 1), morphing into a 'brash suited FT carrying idiot ... egotistical buffoon [and a] greedy ruthless wanker' is a prerequisite for success in investment management. Adopting such an image often proved problematic for women. Roth (2006, p. 94), in her interviews with female Wall Street employees, revealed that 'women faced expectations that they would behave in appropriately feminine ways, even though cultural constructions of femininity clashed with male definitions of managerial competence in Wall Street's male dominated culture'. Brown (1995, p. 41) proposed that the 'rules of the game have become increasingly personalised' and 'the selection of elites has traditionally been associated with a cultural code consistent with images of masculine managerial authority, expert knowledge and the right school tie'. Jones (1998) and McDowell (1997) supported this view of the influence of the old boys' network.

Groysberg (2008) similarly noted that for women 'entering the entrenched culture' of Wall Street there was 'less than wholehearted acceptance' from their male peers. Within the day-to-day working environment, homosocial practices are well embedded and, in order to gain entry, it is necessary to exhibit certain characteristics and personal traits, led by confidence, assertiveness and the ability to be detached and ruthless. McDowell (1997, p. 175) noted that the 'view that women lack the necessary attributes of a successful trader was widespread'. Many men and women within the sector believed that a dealer is by definition 'an aggressive male [and] that's how dealers are, an aggressive woman ... it's not natural' (McDowell 1997, p. 175). Rowe and Crafford (2003, p. 24) similarly cited evidence that female investment managers indicated 'if you try and compete with your male colleagues you are viewed as a bitch'.

The difficulties women face both in entry into and retention within investment management are borne out of widely held beliefs as well as the reality of a range of 
obvious discrimination tactics along with covert exclusionary behaviours. For many women, covert discrimination is far more difficult to address as it's not always possible to articulate. Exclusion strategies such as male gatekeepers, recruitment via the old school tie, male-dominated sporting events for client entertainment and acceptance of laddish behaviour as the norm in the office are examples of 'exclusionary closure' tactics (Davies, 1996, p. 662) and 'effective closure regimes' (Bolton and Muzio, 2007, p. 47). The ideology of 'closure' has been defined by Parkin (1974, p. 3) as 'the process by which social collectives seek to maximize rewards by restricting access to rewards and opportunities to a limited circle of eligibles'. These references to exclusion and closure behaviours have a common foundation in Weber's 'social closure' theory, which has its traditions in the field of sociology (Weber, 1922), and this theory may have validity within the domain of investment management and explaining why women are absent.

'Closure', according to Weber, denotes 'the more or less intentional process of groups drawing boundaries against outsiders, driven not only by economic interests but also by tradition of affectual bonds' (Cardona, 2013, p. 2). Closure regimes have emerged as successful strategies within elite professions like investment management to facilitate 'boundary drawing' and ensure that women are excluded (Costen, Hardigree and Testagrossa, 2012, p. 3). Social closure theory is built on the premise that women and men are different, particularly in relation to their personality traits. As such, female potential entrants' 'differences' to their male peers can be used as a 'defence mechanism' (Ashley, 2010, p. 4) by men to highlight and perpetrate the view that women do not fit with the culture of the sector. By erecting barriers and drawing boundaries in a 'hostile' environment, women can be discouraged from considering investment management as a career path and those who do enter the sector are ultimately excluded from the investment floor, thus ensuring that men can maintain their position, power and status and keep women 'outside the club'.

The literature review has indicated that occupational choice of men and women is influenced by a number of factors, most notably social and individual-led factors, and in particular perceptions about life in certain occupations, expectations about career success and the necessity of personality fit. The literature also proposed that gender, personality traits and occupational choice are related and this is acutely evident when examining why individuals select non-traditional educational and occupational choices. In the case of investment management, research concerning potential entrants and why they opt in (or out) of the sector is absent in an Irish context; however, a large body of research concerning the societal perceptions of working life in the front office of investment management exists. The evidence suggests an image and indeed a reality of a culture that is patriachial in nature and nurtures a driven, aggressive and fast-paced, dynamic environment. This research aims to examine what are the perceptions of postgraduate finance students, as potential entrants to investment management, regarding the sector. Thereafter whether men and women differ in their views is explored and the influence (if any) of experience on men and women's views is examined. Such an examination allows us to establish whether within an Irish context women are opting out of the sector because they believe they do not have the 'right fit'. 
Sheerin

\section{RESEARCH METHODOLOGY}

The primary methodological approach when examining life in investment management has been through the use of interviews (McDowell, 1997; Jones, 1998; Rowe and Crafford, 2003; Pryce and Sealy, 2013). This research aims to introduce some quantitative analysis into the body of knowledge concerning investment management. Specifically, this study examines if any statistically significant differences exist between men and women concerning their belief about what personality traits are considered necessary to succeed within the sector. This question was examined via the use of a questionnaire survey that was completed by 191 respondents. The survey was an original research tool and was a purposeful choice influenced by the non-existence of a suitable standardised and validated questionnaire in the literature.

The questionnaire survey was developed based on the results from two focus groups and relevant literature. Focus groups were held with postgraduate students in finance. One focus group was conducted with full-time students undertaking an MSc in Finance who were considered to be potential entrants to the sector and had no work experience. The second focus group was undertaken with part-time students who had some experience of working in the investment management sector full-time and were studying part-time. Focus group participants were asked to discuss the factors they considered essential for survival and success within investment management. The less structured nature of the focus groups enabled participants to express opinions in an unconstrained manner and explore their attitudes in response to the remarks of other respondents, thus revealing greater insights about the research problem. The focus group discussions were recorded and the results were subsequently compared with relevant literature. A detailed phase of analysis with multi-stage coding was undertaken using N-Vivo 9. The analysis phase confirmed a substantial amount of correlation between the focus group responses and the existing literature, which had highlighted assertiveness, confidence, leadership skills and working under pressure among the essential skills considered necessary for employment. The results of the analysis led to a final cluster of ten factors considered important for career success in investment management, as seen in Table 1.

TABLE I: CAREER SUCCESS IN INVESTMENT MANAGEMENT

Assertiveness
Communication skills
Good at numeracy-based subjects
Ability to network
Team player
Personal initiative
Confidence
Problem-solver
Ability to work well under pressure
Good leadership skills


The questionnaire survey contained the ten factors as presented in Table 1 and asked respondents to rank, in order of preference on a five-point Likert scale, the importance of each factor for a career in investment management. The continuum extended from 'Very Important' to 'Very Unimportant'. Specifically, Likert scales were adopted for use within this study as they facilitate the measurement of 'attitudes, providing a range of responses to a given question or statement' (Jamieson, 2004, p. 1212). Cronbach's alpha, which measures the internal consistency of the scale items, was 96 per cent, indicating a high level of internal reliability in the measurement scale.

The sample was comprised of students undertaking postgraduate study in finance across the Irish third-level sector. This included the university sector, the institute of technology sector and privately owned colleges. The criteria for inclusion required respondents to be studying either part-time or full-time. Students undertaking postgraduate programmes that were dual honours in nature, for example an MSc in Finance and Economics or an MSc in Finance and Accounting, were also considered for inclusion. The final sample consisted of seven academic institutions (Table 2).

TABLE 2: QUESTIONNAIRE SURVEY SAMPLE $(\mathbf{N}=191)$

\begin{tabular}{|c|c|c|c|c|c|}
\hline \multirow[t]{2}{*}{ Institution } & \multicolumn{2}{|c|}{ Programme of Study } & \multirow[t]{2}{*}{ Population } & \multirow[t]{2}{*}{ Sample } & \multirow{2}{*}{$\begin{array}{l}\text { \% Response Rate } \\
\text { by Institution }\end{array}$} \\
\hline & $\begin{array}{l}\text { MSc/MA in } \\
\text { Finance }\end{array}$ & $\begin{array}{l}\text { MSc in Finance } \\
\text { (Dual Honours) }\end{array}$ & & & \\
\hline Institution A & $\checkmark$ & & 25 & 20 & $80 \%$ \\
\hline \multirow[t]{2}{*}{ Institution B } & & $\checkmark$ & 26 & 21 & $79 \%$ \\
\hline & $\checkmark$ & & 32 & 31 & \\
\hline Institution C & & $\checkmark$ & 46 & 43 & $93 \%$ \\
\hline \multirow[t]{3}{*}{ Institution D } & $\checkmark$ & & 12 & 7 & $84 \%$ \\
\hline & & $\checkmark$ & 22 & 17 & \\
\hline & & $\checkmark$ & 36 & 35 & \\
\hline Institution E & $\checkmark$ & & 17 & 17 & $100 \%$ \\
\hline \multirow[t]{2}{*}{ Institution F } & $\checkmark$ & & 25 & 0 & $0 \%$ \\
\hline & $\checkmark$ & & 20 & 0 & \\
\hline \multirow[t]{2}{*}{ Institution G } & & $\checkmark$ & 20 & 0 & $0 \%$ \\
\hline & & $\checkmark$ & 30 & 0 & \\
\hline Total & & & 311 & 191 & $61 \%$ \\
\hline
\end{tabular}

Of these seven institutions, five facilitated direct access to students. Within these institutions, the questionnaires were administered in paper-based format for selfcompletion by respondents. The sample group was comprised of students with experience of working in investment management $(n=46)$ who were undertaking their studies part-time and those who did not have any experience of working in the sector $(n=145)$ and were studying full-time. The sample comprised of just below 60 
Sheerin

per cent men and 40 per cent women (Table 3). The majority of participants had no experience of working in the sector $(76 \%)$.

TABLE 3: QUESTIONNAIRE SURVEY SAMPLE $(\mathbf{N}=191)$

\begin{tabular}{llll}
\hline $\begin{array}{c}\text { Respondents According to } \\
\text { Experience \& Gender }(\mathrm{n}=\mathbf{1 9} \text { |) }\end{array}$ & Experience (E) & No Experience (NE) & Total \\
\hline Male & $\mathrm{n}=30(16 \%)$ & $\mathrm{n}=79(41 \%)$ & $\mathrm{n}=109(57 \%)$ \\
Female & $\mathrm{n}=14(7 \%)$ & $\mathrm{n}=62(33 \%)$ & $\mathrm{n}=76(40 \%)$ \\
Gender not declared & $\mathrm{n}=2(1 \%)$ & $\mathrm{n}=4(2 \%)$ & $\mathrm{n}=6(3 \%)$ \\
Total & $\mathrm{n}=46(24 \%)$ & $\mathrm{n}=145(76 \%)$ & $\mathrm{n}=191(100 \%)$ \\
\hline
\end{tabular}

The overall response rate was 61 per cent and this was considered reasonable, compared with other similar studies. Baruch and Holton (2008) undertook a widescale examination of survey response rates across 490 different peer-reviewed research papers and 400,000 individual respondents. They concluded that an average response rate of 62 per cent for surveys that were self-administered was the accepted norm.

\section{ANALYSIS}

In order to provide a context prior to any statistical analysis being undertaken, it was important to ascertain what factors both men and women considered important for survival and success in the sector. Figure 1 illustrates the respondents' ranking of factors affecting career success in investment management, classified by gender.

There is general agreement between men and women concerning the personality traits necessary for success in the sector (Figure 1). Working well under pressure and being confident in one's own ability was highlighted by men and women alike. Men and women differed only in the relative order of factor importance. For men, working well under pressure was ranked most important $(96 \%)$, followed by confidence $(91 \%)$, and assertiveness and communication skills (88\%). For women, communication skills ranked first $(96 \%)$, with the ability to work well under pressure ranking second $(93 \%)$, followed by confidence $(91 \%)$. In order to examine if any statistically significant differences exist between men and women, and indeed whether experience in the sector had an impact, further analysis was necessary using inferential statistics.

The variables within this survey were defined as categorical where categorical data includes both nominal and ordinal measurement scale. Nominal variables included gender, and the Likert scale adopted in this survey is ordinal in nature. Most academics agree that Likert scales are ordinal in nature and as such do not possess a normal probability distribution (Cohen, Manion and Morrison, 2000; Kuzon, Urbanchek and McCabe, 1996). Jamieson (2004, p. 1217) argued that Likert scales are ordinal as 'the response categories have a rank order but the intervals between values cannot be presumed equal'. As a consequence of the data types being ordinal and nominal in nature, non-parametric tests were deemed valid to 


\section{FIGURE I: EXAMINING WHAT IS IMPORTANT FOR A CAREER IN INVESTMENT MANAGEMENT THROUGH THE GENDER LENS $(\mathbf{N}=150)$}

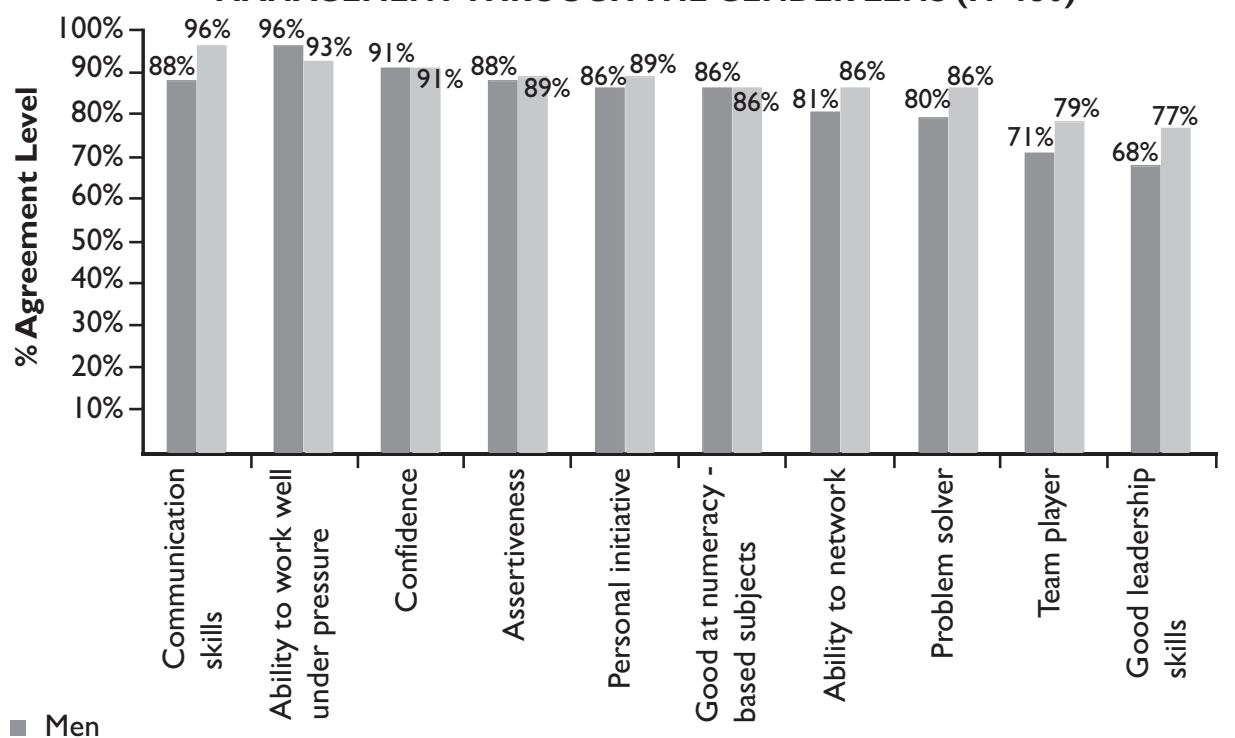

Women Factors affecting career success in investment management

investigate whether a difference existed in the ranks of men and women and hence whether experience impacted the ranked importance attributed to the factors by both genders concerning the traits listed in Table 1. Specifically, the non-parametric statistical test adopted was the Mann-Whitney (U) test. The Mann-Whitney (U) test is the non-parametric equivalent of a traditional t-test for independent samples. Specifically, the hypotheses under examination examined whether men and women have different views concerning factors necessary for survival and success in investment management and whether experience impacts this. Hypothesis 1 sets out to test whether women and men differ in their beliefs while Hypothesis 2 is presented in two parts (a) and (b), which examine the question of whether a difference exists between the genders when experience of the sector is gained (2a), and whether a difference exists within the genders when experience of the sector is gained.

\section{Hypothesis 1}

Ho: There is no systematic difference between men and women with no experience of working in investment management concerning the ranked importance of the factors listed in Table 1.

Ha: There is a systematic difference between men and women with no experience of working in investment management concerning the ranked importance of the factors listed in Table 1.

\section{Hypothesis 2(a) (between the genders)}

Ho: There is no systematic difference between men and women with experience of working in investment management concerning the ranked importance of the factors listed in Table 1. 
Sheerin

Ha: There is a systematic difference between men and women with experience of working in investment management concerning the ranked importance of the factors listed in Table 1.

\section{Hypothesis 2(b) (within the genders)}

Ho: The ranked importance assigned by men (women) concerning the factors listed in Table 1 does not change with experience of working in investment management.

Ha: The ranked importance assigned by men (women) concerning the factors listed in Table 1 does change with experience of working in investment management.

The version of Mann-Whitney adopted for all tests was a two-tailed, nondirectional test. The test results presented represent an asymptotic two-sided test with $p$ value results being considered statistically significant if the relevant asymptotic $p$ value was less than 5 per cent $(p<0.05)$. Statistical Package for the Social Sciences (SPSS) was used to undertake the calculations and the reported $p$ value is the asymptotic (rather than the exact) value, which is in line with Corder and Foreman (2009).

\section{FINDINGS}

The culture of investment management as a cut-throat dynamic and fast-moving sector sets the backdrop for the responses of respondents concerning the personal traits necessary for entry to the sector. In response to what personality traits and characteristics underpin a career in front office investment management, for men and women alike, the ability to work well under pressure, and to be confident and communicate effectively, featured as important. There was evidence of general agreement between men and women concerning the personality traits necessary for success in the sector. Working well under pressure and being confident in one's own ability was highlighted by men and women alike. Men and women differed only in the relative order of factor importance. For men, working well under pressure was ranked most important (96\%), followed by confidence (91\%), and assertiveness and communication skills (88\%). For women, communication skills ranked first (96\%), with the ability to work well under pressure ranking second (93\%), followed by confidence (91\%). These findings are in line with those of McDowell (1997), Rowe and Crafford (2003), Roth (2006), McDowell (2010) and Pryce and Sealy (2013), as well as those concerning related fields of finance such as insurance and retail banking (Burgess, 2003; Ozbilgin and Woodward, 2004; Ogden et al., 2006; Broadbridge et al., 2007).

\section{Hypothesis 1}

For those with no experience of working in the sector, the median response as described in Table 4 indicates that men and women alike considered all the factors presented very important (rank=1) or important (rank=2). The mean rank for men and women is presented in column 5 of Table $4 .^{3}$ The final column indicates the Mann-Whitney (U) test $p$ values. Where the $p$ value is less than 0.005 , the null hypothesis that no difference in the rankings of men and women exist is rejected at the 5 per cent level of significance. Clearly evident from Table 4 is that while women 
attributed more importance to every factor listed, no statistically significant differences existed in the mean rankings of men when compared with women for those with no experience of working in the sector.

TABLE 4: NO EXPERIENCE OF WORKING IN INVESTMENT MANAGEMENT: WHAT PERSONAL CHARACTERISTICS ARE IMPORTANT: MENVWOMEN?

$(\mathrm{N}=|40-| 4 \mid)$

\begin{tabular}{|c|c|c|c|c|c|}
\hline & Gender & $\mathbf{N}$ & $\begin{array}{c}\text { Median } \\
\text { Response }\end{array}$ & $\begin{array}{l}\text { Mean } \\
\text { Rank }\end{array}$ & $\begin{array}{c}\text { Mann-Whitney }(U) \\
\text { test ( } P \text { value) }\end{array}$ \\
\hline \multirow[t]{2}{*}{ Assertiveness } & Male & 79 & 1 & 73.04 & 0.482 \\
\hline & Female & 62 & 1 & 68.40 & \\
\hline \multirow{2}{*}{$\begin{array}{l}\text { Good at numeracy-based } \\
\text { subjects }\end{array}$} & Male & 78 & 1 & 72.97 & 0.398 \\
\hline & Female & 62 & 1 & 67.39 & \\
\hline \multirow[t]{2}{*}{ Communication skills } & Male & 79 & I & 74.05 & 0.282 \\
\hline & Female & 62 & I & 67.11 & \\
\hline \multirow[t]{2}{*}{ Team player } & Male & 79 & 2 & 74.30 & 0.191 \\
\hline & Female & 61 & 1 & 65.57 & \\
\hline \multirow[t]{2}{*}{ Personal initiative } & Male & 79 & 1 & 71.44 & 0.880 \\
\hline & Female & 62 & 1 & 70.44 & \\
\hline \multirow[t]{2}{*}{ Confidence } & Male & 79 & 1 & 73.08 & 0.355 \\
\hline & Female & 61 & 1 & 67.16 & \\
\hline \multirow[t]{2}{*}{ Ability to network } & Male & 79 & 1 & 73.20 & 0.452 \\
\hline & Female & 62 & 1 & 68.20 & \\
\hline \multirow[t]{2}{*}{ Problem-solver } & Male & 79 & 2 & 75.61 & 0.114 \\
\hline & Female & 62 & 1 & 65.12 & \\
\hline \multirow{2}{*}{$\begin{array}{l}\text { Ability to work well under } \\
\text { pressure }\end{array}$} & Male & 79 & 1 & 72.40 & 0.621 \\
\hline & Female & 62 & 1 & 69.22 & \\
\hline \multirow[t]{2}{*}{ Good leadership skills } & Male & 79 & 2 & 73.92 & 0.242 \\
\hline & Female & 61 & 1 & 66.07 & \\
\hline
\end{tabular}

Hypothesis 2

The question concerning experience was examined from the perspective of whether experience influenced the beliefs of men (women) when compared with women (men) as well as within the genders. Table 5 sets out the results for whether a difference exists between the genders once experience of working in investment management is acquired. From Table 5, it is clearly evident that for those with experience $(n=46)$, differences between the genders were clearly apparent. Within Table 5 , where a statistical difference was identified between the mean ranks of men and women, effect size was reported. Effect size was calculated based on Rosenthal's (1991, p. 19) measure of $r$ where $r=|z / \sqrt{ } n|$. Field (2009, p. 57), in line with Rosenthal (1991), defines effect size according to the following scale: $r<0.3$ : effect size is small; $0.3<r<0.5$ : effect size is medium; and $r>0.5$ : effect size is large. 
Sheerin

\begin{tabular}{|c|c|c|c|c|c|c|}
\hline Characteristic & Gender & $\mathbf{N}$ & $\begin{array}{c}\text { Median } \\
\text { Response } \\
\end{array}$ & $\begin{array}{l}\text { Mean } \\
\text { Rank }\end{array}$ & $\begin{array}{c}\text { Mann-Whitney } \\
(U) \text { test ( } P \text { value) }\end{array}$ & $\begin{array}{l}\text { Effect } \\
\text { Size }\end{array}$ \\
\hline \multirow[t]{2}{*}{ Assertiveness } & Male & 30 & 2 & 25.93 & 0.005 & $(r=-0.4 I)$ \\
\hline & Female & 14 & I & 15.14 & & \\
\hline \multirow{2}{*}{$\begin{array}{l}\text { Sood at numeracy- } \\
\text { based subjects }\end{array}$} & Male & 30 & 2 & 24.38 & 0.122 & \\
\hline & Female & 14 & I & 18.46 & & \\
\hline \multirow{2}{*}{$\begin{array}{l}\text { Communication } \\
\text { skills }\end{array}$} & Male & 30 & 2 & 25.13 & 0.032 & $(r=-0.3 \mathrm{I})$ \\
\hline & Female & 14 & I & 16.86 & & \\
\hline \multirow[t]{2}{*}{ eam player } & Male & 30 & 2 & 25.05 & 0.045 & $(r=-0.30)$ \\
\hline & Female & 14 & I & 17.04 & & \\
\hline \multirow[t]{2}{*}{ ersonal initiative } & Male & 30 & 2 & 25.97 & 0.005 & $(r=-0.4 I)$ \\
\hline & Female & 14 & I & 15.07 & & \\
\hline \multirow[t]{2}{*}{ Zonfidence } & Male & 30 & 2 & 26.27 & 0.002 & $(r=-0.46)$ \\
\hline & Female & 14 & I & 14.43 & & \\
\hline \multirow[t]{2}{*}{ Ability to network } & Male & 30 & 2 & 26.02 & 0.005 & $(r=-0.41)$ \\
\hline & Female & 14 & I & 14.96 & & \\
\hline \multirow[t]{2}{*}{ roblem-solver } & Male & 30 & 2 & 24.83 & 0.062 & \\
\hline & Female & 14 & I & 17.50 & & \\
\hline \multirow{2}{*}{$\begin{array}{l}\text { bility to work well } \\
\text { under pressure }\end{array}$} & Male & 30 & I & 24.77 & 0.056 & \\
\hline & Female & 14 & I & 17.64 & & \\
\hline \multirow{2}{*}{$\begin{array}{l}\text { Jood leadership } \\
\text { skills }\end{array}$} & Male & 30 & 2 & 25.35 & 0.024 & $(r=-0.34)$ \\
\hline & Female & 14 & I & 16.39 & & \\
\hline
\end{tabular}

Table 4 shows that in all cases of gender difference, women attributed a higher level of importance to the factors than men. ${ }^{4}$ In particular, women with work experience highlighted the importance of confidence $(p=0.002)$, assertiveness $(p=0.005)$, ability to network $(p=0.005)$ and personal initiative $(p=0.005)$ more highly than did their male peers. The effect size in each case was considered medium. In the case of communication skills, being a team player and good leadership skills, a statistically significant difference in the mean rankings of men and women was noted. Although the statistical difference was deemed small (see effect size), women did rank these factors consistently higher than did their male peers.

The findings thus far reveal that women when compared with men who had gained experience of the sector had much stronger views regarding the necessary personality traits for survival. Tables 6 and 7 set out the results when the question of whether women's (or men's) views altered when experience of the sector was obtained. Results from Table 6 indicate that for men with and without experience of working in investment management, a difference exists concerning the ranked importance of the factors presented. Interestingly, the results indicate that men with no experience of working in the sector rank assertiveness, communication, 
TABLE 6: PERSONAL CHARACTERISTICS AND INVESTMENT MANAGEMENT: MEN WITH NO EXPERIENCE V MEN WITH EXPERIENCE $(\mathrm{N}=109)$

\begin{tabular}{|c|c|c|c|c|c|c|}
\hline Characteristic & Experience & $\mathbf{N}$ & $\begin{array}{c}\text { Median } \\
\text { Response }\end{array}$ & $\begin{array}{l}\text { Mean } \\
\text { Rank }\end{array}$ & $\begin{array}{l}\text { Mann-Whitney } \\
\text { (U) test ( } P \text { value) }\end{array}$ & $\begin{array}{l}\text { Effect } \\
\text { Size }\end{array}$ \\
\hline \multirow[t]{2}{*}{ Assertiveness } & Experience & 30 & 2 & 67.80 & 0.006 & $(r=0.27)$ \\
\hline & No experience & 79 & I & 50.14 & & \\
\hline \multirow{2}{*}{$\begin{array}{l}\text { Good at numeracy- } \\
\text { based subjects }\end{array}$} & Experience & 30 & 2 & 60.10 & 0.224 & \\
\hline & No experience & 79 & I & 52.35 & & \\
\hline \multirow{2}{*}{$\begin{array}{l}\text { Communication } \\
\text { skills }\end{array}$} & Experience & 30 & 2 & 68.48 & 0.003 & $(r=0.28)$ \\
\hline & No experience & 79 & I & 49.88 & & \\
\hline \multirow[t]{2}{*}{ Team player } & Experience & 30 & 2 & 63.33 & 0.079 & \\
\hline & No experience & 79 & 2 & 51.84 & & \\
\hline \multirow[t]{2}{*}{ Personal initiative } & Experience & 30 & 2 & 68.85 & 0.003 & $(r=0.29)$ \\
\hline & No experience & 79 & I & 49.74 & & \\
\hline \multirow[t]{2}{*}{ Confidence } & Experience & 30 & 2 & 71.45 & 0.000 & $(r=0.35)$ \\
\hline & No experience & 79 & I & 48.75 & & \\
\hline \multirow[t]{2}{*}{ Ability to network } & Experience & 30 & 2 & 66.40 & 0.015 & $(r=0.23)$ \\
\hline & No experience & 79 & I & 50.67 & & \\
\hline \multirow[t]{2}{*}{ Problem-solver } & Experience & 30 & 2 & 62.55 & 0.108 & \\
\hline & No experience & 79 & 2 & 52.13 & & \\
\hline \multirow{2}{*}{$\begin{array}{l}\text { Ability to work well } \\
\text { under pressure }\end{array}$} & Experience & 30 & I & 65.97 & 0.014 & $(r=0.23)$ \\
\hline & No experience & 79 & I & 50.84 & & \\
\hline \multirow{2}{*}{$\begin{array}{l}\text { Good leadership } \\
\text { skills }\end{array}$} & Experience & 30 & 2 & 63.05 & 0.092 & \\
\hline & No experience & 79 & 2 & 51.94 & & \\
\hline
\end{tabular}

TABLE 7: PERSONAL CHARACTERISTICS AND INVESTMENT MANAGEMENT: WOMEN WITH NO EXPERIENCE $V$ WOMEN WITH EXPERIENCE $(\mathrm{N}=76)$

\begin{tabular}{|c|c|c|c|c|c|}
\hline Characteristic & Experience & $\mathbf{N}$ & $\begin{array}{c}\text { Median } \\
\text { Response }\end{array}$ & $\begin{array}{l}\text { Mean } \\
\text { Rank }\end{array}$ & $\begin{array}{c}\text { Mann-Whitney }(U) \\
\text { test ( } P \text { value) }\end{array}$ \\
\hline \multirow[t]{2}{*}{ Assertiveness } & Experience & 14 & 1 & 37.00 & 0.768 \\
\hline & No experience & 62 & I & 38.84 & \\
\hline \multirow{2}{*}{$\begin{array}{l}\text { Good at numeric- } \\
\text { based subjects }\end{array}$} & Experience & 14 & I & 38.46 & 0.994 \\
\hline & No experience & 62 & I & 38.51 & \\
\hline \multirow[t]{2}{*}{ Communication skills } & Experience & 14 & I & 41.43 & 0.554 \\
\hline & No experience & 62 & I & 37.84 & \\
\hline \multirow[t]{2}{*}{ Team player } & Experience & 14 & I & 38.04 & 0.994 \\
\hline & No experience & 62 & I & 37.99 & \\
\hline \multirow[t]{2}{*}{ Personal initiative } & Experience & 14 & I & 35.61 & 0.569 \\
\hline & No experience & 62 & I & 39.15 & \\
\hline
\end{tabular}

(Continued) 
Sheerin

TABLE 7 (CONTINUED)

\begin{tabular}{llcccc}
\hline Characteristic & Experience & N & $\begin{array}{c}\text { Median } \\
\text { Response }\end{array}$ & $\begin{array}{c}\text { Mean } \\
\text { Rank }\end{array}$ & $\begin{array}{c}\text { Mann-Whitney (U) } \\
\text { test (P value) }\end{array}$ \\
\hline Confidence & Experience & 14 & $\mathrm{I}$ & 38.50 & 0.917 \\
Ability to network & No experience & 62 & $\mathrm{I}$ & 37.89 & \\
& Experience & 14 & $\mathrm{I}$ & 35.25 & 0.523 \\
& No experience & 62 & $\mathrm{I}$ & 39.23 & \\
Problem-solver & Experience & 14 & $\mathrm{I}$ & 39.68 & 0.817 \\
& No experience & 62 & $\mathrm{I}$ & 38.23 & \\
Ability to work well & Experience & 14 & $\mathrm{I}$ & 39.25 & 0.880 \\
under pressure & No experience & 62 & $\mathrm{I}$ & 38.33 & \\
Good leadership & Experience & 14 & $\mathrm{I}$ & 36.39 & 0.752 \\
skills & No experience & 62 & $\mathrm{I}$ & 38.37 & \\
\hline
\end{tabular}

confidence, personal initiative and ability to network as more important than their male peers working within the sector. The most prominent evidence of this difference was for confidence and personal initiative.

For women, experience of the sector did not cause any factor to be ranked differently, with women's views remaining consistent from pre-entry to life within the sector (Table 7).

\section{CONCLUSIONS}

In examining the findings using the lens of gender and then experience, it is clearly evident that all respondents, regardless of gender or experience, agree on the importance of confidence, assertiveness, numeracy skills and working well under pressure within investment management. For those with no experience of working in the sector, no statistically significant difference between the genders was evident. This suggests that from an Irish educational point of view, an unbiased view of the opportunities and hurdles in investment management is presented to male and female students alike. For those men and women who have worked in investment management, women systematically ranked a number of factors - including confidence, ability to network, assertiveness and personal initiative - as more important skills for survival and success more highly than their male peers. This concurs with the findings of McDowell (1997), Rowe and Crafford (2003), Roth (2003), Anderson (2009) and Thompson (2010), who all drew inferences wherein women felt they had to adopt wolfish characteristics of assertiveness and confidence and conform to the masculine ideology if they were to survive and succeed in investment management.

For women, the views of potential entrants to the sectors when compared with those working in the sector yielded no statistically significant differences. This indicates a similar outlook and set of perceptions and beliefs being held by those women outside the club and those women inside the club. Similarly, Roth (2006), Jones (1998) and McDowell (1997, 2010), in a US and UK context respectively, 
highlighted the perceptions and beliefs of women concerning their need to demonstrate aggression, assertiveness and confidence both when seeking employment within investment management and once employed within the sector. These results also suggest that social closure theory may have validity in explaining the absence of women from front office investment management. Women inside and outside the sector recognise that in order to gain acceptance by their male peers, and to attempt to overcome the covert discriminatory characteristics and exclusion tactics that are entrenched within the culture of the sector, they need to adopt certain behaviours. In the words of Lewis (1989, p. 53), 'everyone wants to be a big swinging dick, even the women ... big swinging dickettes'.

For men, interestingly, potential entrants attribute more importance to assertiveness, communication skills, personal initiative, confidence, ability to network and ability to work well under pressure than their male peers already working in the sector. One possible explanation is that men inside the sector enjoy preferential treatment when compared to their female colleagues, purely as a consequence of their gender. This explanation is in line with Anderson (2009) who indicated that inside the sector he realised that being male was enough to put him at an advantage when compared with female counterparts. He indicated that this was apparent even from the early stages of his career where he was told 'you had the job five minutes into the interview. We need sharp, cocky dickheads and you fit the bill nicely' (Anderson, 2009, p. 24). Similarly, Jones (1998) presented findings whereby women were seen as 'outsiders' while men once inside the sector recognised they were very much the right 'fit' for the sector. Such 'tactical opportunism' (Bolton and Muzio, 2007, p. 49) facilitates development of ideologies whereby if women have to be let into the sector, boundaries can be drawn to ensure they are 'cordoned off' or 'ringfenced' within less prestigious roles that they are 'more suited to' rather than front office roles, again giving credence to the validity of social closure theory in explaining why women are absent from front office investment management roles.

In summary, the findings from this study show that women and men agree on the importance of certain 'wolfish' characteristics for success and survival in investment management. The results reinforce the view that women feel they need to behave like men in order to survive and this is a widely held belief among women both inside and outside the sector. The findings also indicate that men, once inside the sector, do not attribute the same level of importance to certain factors as they did as potential entrants. As is portrayed in The Wolf of Wall Street and reinforced every day by various facets of society, investment management is dominated by men and this in itself is a prerequisite for success. These findings highlight the advantaged status of men and reinforce the view that within investment management, like many other male-dominated fields, 'they [women] must work harder than men for the same rewards' (Brett and Stroh, 2003, p. 76).

\section{Implications of Findings and Recommendations}

The findings from this research indicate that gender stereotypes, both real and perceived, remain a barrier for women in investment management. In order to address this concern, change needs to be enacted at a societal, organisational and individual level. At a societal level, the European Commission has stated that safeguarding 
Sheerin

gender equality, particularly within the labour market, is essential for economic progress (European Commission, 2012). As such, within male-dominated sectors like investment management a framework of national, governmental and international policies as well as investment in gender equality legislation needs to be implemented and monitored. Rees (2005) argues that such a framework must highlight the consequences of gender inequality in terms of the 'business case' in order to get 'buy in' from firms. She argues that if business sectors understand the importance of gender equality and appreciate how diversity in talent and the inclusion of women in decision-making will contribute to the bottom line they will enact change. Gender equality must be reframed as an economic concern rather than a social justice issue, with the understanding that gender diversity is essential to ensuring innovative and diverse research.

At a societal level, educators also have a role in highlighting gender inequality and the importance of diversity across the labour market. As such, learning outcomes of programme curricula should consider the inclusion of content relating to organisational cultures, diversity and gender inequality. Equally, developing an understanding among graduates of the skill set and attributes considered important for certain occupations and facilitating them in developing a more transferable range of skills that are gender-neutral is essential in preparing them for the working environment ahead.

At an organisational level, the need for workplace reform is essential in order to deconstruct the perceptions and beliefs that women do not 'fit' within front office investment management roles. Specifically, change in terms of the recruitment and promotion processes as well as everyday work practices is necessary. Clear and transparent recruitment and progression policies articulating job requirements and hiring policies are needed. Equally, gender-balanced interview panels that have clear criteria set out for assessing candidates are essential in ensuring that employees are not recruited/promoted because they simply 'fit the bill nicely' (Anderson, 2009, p. 24).

In terms of work practices, men and women alike agreed that investment management is underpinned by an extreme male-dominated culture where working well under pressure is essential for success. To ensure the patriarchal environment moves to a more gender-neutral space, organisations must commit to initiatives such as periodic reviews of institutional practices and policies to ensure that gender equality is an active and live concern among all stakeholders. Organisations also need to commit to ensuring sanctions are set out for those in breach of dignity and respect policies in the workplace. These sanctions need to be enforced regardless of seniority, ability or the profit-making ability of the individual breaching regulations.

Finally, at an individual level, men and women will inevitably behave in a way that benefits them. This often leads to 'closure regimes' created by male and female 'elites' inside the front office. In order to tackle this issue, increased awareness needs to be highlighted for male and female elites alike. For men working in the front office, fostering the view that women are not a threat to their position is vital. For women working in the front office, awareness of the need to reach out to other women as opposed to adopting the 'Queen Bee' philosophy is needed. Similarly, understanding that perpetration of damaging assumptions (e.g. Women's 
commitment to work is undermined by their potential to have a baby) is detrimental to the progression and success of all women.

\section{Limitations and Future Research}

This research, using the lens of gender, has examined what perceptions and beliefs are held among potential entrants and those inside the investment management sector regarding the necessary personality traits for success and survival. While the research has provided understanding concerning this issue, it is not without its limitations. Specifically, survey respondents were drawn from postgraduate finance programmes. This is the most direct route to an investment management career and as such was the criterion for being included in the sampling frame. However, it is not the only route to a career in investment management. Future studies should also examine the perceptions of engineering, mathematics and statistics postgraduate students, as well as chartered financial analyst (CFA) participants, in order to have a more comprehensive sample of potential entrants. Furthermore, this research elicited the views of those who had already expressed an interest in a career in investment management by undertaking postgraduate study in finance. Further studies should consider the views of those students who considered and rejected investment management as a career option in order to better understand perceptions about the sector as well as reasons why people opt out altogether.

In extending the research, the use of interviews alongside the focus groups and surveys would benefit this study. The findings herein clearly indicate that women, both potential entrants and investment management employees, see maleassociated traits of aggression, assertiveness and confidence as far more important and valuable that their inherent feminine traits. The use of interviews to explore this further and extend the analysis to investigate why women feel this way would add significant value to the body of knowledge. Equally, interviewing men and asking those inside the sector why they changed their views in terms of a lesserranked importance being placed on certain traits, once inside the sector, and if this is because being male is enough.

\section{ENDNOTES}

ISCED (Intentional Standard Classification of Education) 343 Finance, Banking and Insurance.

In 2009, 1,091 students undertook undergraduate finance programmes of whom 54 per cent $(n=585)$ were male and 46 per cent female ( $n=506$ ). In 2008, of the 1,272 students enrolled on finance programmes, 49 per cent were male $(n=630)$ compared with 51 per cent female $(n=642)$.

3 The group with the lowest mean rank is the group that considers the relevant factor under consideration more important. Similarly, the group with the highest mean rank should have greater number of high scores within it and as such allocate less importance to the factor under consideration.

$4 \quad$ The direction of difference was estimated using mean ranks.

\section{REFERENCES}

Adeyemo, D.A. (2005). Parental Involvement, Interest in Schooling and School Environment as Predictors of Academic Self-Efficacy among Fresh Secondary School Students 
Sheerin

in Oyo State, Nigeria, Electronic Journal of Research in Educational Psychology, Vol. 3, No. 1, pp. 163-180.

Adya, M. and Kaiser, K.M. (2005). Early Determinants of Women in the IT Workforce: A Model of Girls' Career Choices, Information Technology \& People, Vol. 18, No. 3, pp. 230-259.

Adya, M.P. (2008). Women at Work: Differences in IT Career Experiences and Perceptions between South Asian and American Women, Human Resource Management, Vol. 47, No. 3, pp. 601-635.

Anderson, G. (2009). Cityboy: Beer and Loathing in the Square Mile, London: Headline.

Ashley, L. (2010). 'They're Not All Bastards': Prospects for Gender Equality in the UK's Elite Law Firms, 23 December, Cass Centre for Professional Service Firms Working Paper.

Bandura, A., Barbaranelli, C., Caprara, G.V. and Pastorelli, C. (2001). Self-Efficacy Beliefs as Shapers of Children's Aspirations and Career Trajectories, Child Development, Vol. 72, No. 1, pp. 187-206.

Barker, P.C. and Monks, K. (1998). Irish Women Accountants and Career Progression: A Research Note, Accounting, Organizations and Society, Vol. 23, No. 8, pp. 813-823.

Baruch, Y. and Holtom, B.C. (2008). Survey Response Rate Levels and Trends in Organizational Research, Human Relations, Vol. 61, No. 8, pp. 1139-1160.

Bevan, V. and Learmonth, M. (2013). 'I Wouldn't Say It's Sexism, Except that ... It's All These Little Subtle Things': Healthcare Scientists' Accounts of Gender in Healthcare Science Laboratories, Social Studies of Science, Vol. 43, No. 1, pp. 136-158.

Bolton, S.C. and Muzio, D. (2007). Can't Live with 'Em; Can't Live without 'Em: Gendered Segmentation in the Legal Profession, Sociology, Vol. 41, No. 1, pp. 47-64.

Borghans, L., Duckworth, A.L., Heckman, J.J. and ter Weel, B. (20080. The Economics and Psychology of Personality Traits, February, Institute of Study of Labor (IZA) Discussion Paper No. 3333 [online], available from: <http://ftp.iza.org/dp3333.pdf>, accessed 11 March 2015.

Brett, J.M. and Stroh, L.K. (2003). Working 61 Plus Hours a Week: Why Do Managers Do It?, Journal of Applied Psychology, Vol. 88, No. 1, pp. 67-78.

Broadbridge, A.M., Maxwell, G.A. and Ogden, S.M. (2007). Students' Views of Retail Employment-Key Findings from Generation Ys, International Journal of Retail \& Distribution Management, Vol. 35, No. 12, pp. 982-992.

Brown, B.B. (2004). Adolescents' Relationships with Peers in R.M. Lerner and L. Steinberg (eds.), Handbook of Adolescent Psychology, second edition, Hoboken, NJ: John Wiley \& Sons, pp. 363-394.

Brown, P. (1995). Cultural Capital and Social Exclusion: Some Observations on Recent Trends in Education, Employment and the Labour Market, Work, Employment and Society, Vol. 9, No. 1, pp. 29-51.

Burgess, C. (2003). Gender and Salaries in Hotel Financial Management: It's still a Man's World, Women in Management Review, Vol. 18, Nos. 1/2, pp. 50-59.

Cardona, A. (2013). Closing the Group or the Market? The Two Sides of Weber's Concept of Closure and Their Relevance for the Study of Intergroup Inequality, SFB 882 Working Paper Series No. 15, DFG Research Centre, University of Bielefeld, Germany.

Cobb-Clark, D. and Tan, M. (2009). Noncognitive Skills, Occupational Attainment, and Relative Wages, July, Institute for the Study of Labor (IZA) Discussion Paper No. 4289 [online], available from: <http://ftp.iza.org/dp4289.pdf>, accessed 11 March 2015.

Cohen, L., Manion, L. and Morrison, K. (2000). Research Methods in Education, fifth edition, London: Routledge.

Corder, G.W. and Foreman, D.I. (2009). Nonparametric Statistics for Non-Statisticians: A Step-byStep Approach, Hoboken, NJ: John Wiley \& Sons. 
The (She) Wolf of Wall Street

Costen, W.M., Hardigree, C.E. and Testagrossa, M.A. (2012). Glass Ceiling or Saran Wrap ${ }^{\mathrm{TM}}$ ? Women in Gaming Management, UNLV Gaming Research and Review Journal, Vol. 7, No. 2, pp. 1-12.

Davidson, M.J. and Burke, R.J. (1994). Women in Management: Current Research Issues, London: Paul Chapman Publishing.

Davies, C. (1996). The Sociology of Professions and the Profession of Gender, Sociology, Vol. 30, No. 4, pp. 661-678.

Davies, L. (2012). Trading Places, South China Morning Post [online], 10 June, available from: <http:/ / www.scmp.com/article/70071/trading-places>, accessed 11 March 2015.

Eccles, J.S. (1994). Understanding Women's Educational and Occupational Choices, Psychology of Women Quarterly, Vol. 18, No. 4, pp. 585-609.

Eccles, J.S. (2009). Who Am I and What Am I Going to Do with My Life? Personal and Collective Identities as Motivators of Action, Educational Psychologist, Vol. 44, No. 2, pp. 78-89.

Ely, R.J. (1995). The Power in Demography: Women's Social Constructions of Gender Identity at Work, Academy of Management Journal, Vol. 38, No. 3, pp. 589-634.

Estes, R. and Hosseini, J. (1988). The Gender Gap on Wall Street: An Empirical Analysis of Confidence in Investment Decision Making, Journal of Psychology, Vol. 122, No. 6, pp. 577-590.

European Commission (2012). Structural Change in Research Institutions: Enhancing Excellence, Gender Equality and Efficiency in Research and Innovation, EUR 24905 EN, Brussels: Commission of the European Communities.

Field, A. (2009). Discovering Statistics Using SPSS (and sex and drugs and rock ' $n$ ' roll), third edition, Thousand Oaks, CA; London: Sage Publications.

Forfás (2007). Future Skills and Research Needs of the International Financial Services Industry (Report of the Expert Group on Future Skills Needs), December, Dublin: Forfás.

Furnham, A. and Fudge, C. (2008). The Five Factor Model of Personality and Sales Performance, Journal of Individual Differences, Vol. 29, No. 1, pp. 11-16.

Greene, J.C., Caracelli, V.J. and Graham, W.F. (1989). Towards a Conceptual Framework for Mixed Methods Evaluation Designs, Educational Evaluation and Policy Analysis, Vol. 11, No. 3, pp. 255-274.

Groysberg, B. (2008). How Star Women Build Portable Skills, Harvard Business Review, February.

Hakim, C. (2002). Lifestyle Preferences as Determinants of Women's Differentiated Labor Market Careers, Work and Occupations, Vol. 29, No. 4, pp. 428-459.

Ham, R., Junankar, P.N. (Raja) and Wells, R. (2009). Occupational Choice: Personality Matters, April, Institute of Study of Labor (IZA) Discussion Paper No. 4105.

Hargreaves, D. (2008). Lap Dance Ethos at Heart of City Sexism, Say Campaigners, The Guardian, 31 March.

Heckman, J.J., Stixrud, J. and Urzua, S.S. (2006). The Effects of Cognitive and Noncognitive Abilities on Labor Market Outcomes and Social Behavior, February, National Bureau of Economic Research Working Paper No. 12006.

Hegewisch, A., Liepmann, H., Hayes, J. and Hartmann, H. (2010). Separate and Not Equal? Gender Segregation in the Labor Market and the Gender Wage Gap, September, Institute for Women's Policy Research Briefing Paper C377.

Hewlett, S.A. and Luce, C.B. (2006). Extreme Jobs: The Dangerous Allure of the 70-Hour Workweek, Harvard Business Review, Vol. 84, No. 12, pp. 49-59.

Higher Education Authority (2013). Higher Education Statistics: Irish National Student Survey, Higher Education Authority [online], available from: <http:/ / www.hea.ie/content/ statistics>, accessed 11 March 2015.

Holland, J.L. (1996). Exploring Careers with a Typology: What We Have Learned and Some New Directions, American Psychologist, Vol. 51, No. 4, pp. 397-406. 
Sheerin

Jamieson, S. (2004). Likert Scales: How to (Ab)use Them, Medical Education, Vol. 38, No. 12, pp. 1217-1218.

Johnson, P.A. (2013). The State of Women in Civil Engineering in the US and the Role of ASCE, Journal of Professional Issues in Engineering Education and Practice, forthcoming.

Jones, A. (1998). (Re)Producing Gender Cultures: Theorizing Gender in Investment Banking Recruitment, Geoforum, Vol. 29, No. 4, pp. 451-474.

Kemelgor, C. and Etzkowitz, H. (2001). Overcoming Isolation: Women's Dilemmas in American Academic Science, Minerva, Vol. 39, No. 2, pp. 153-174.

Kuzon Jr, W.M., Urbanchek, M.G. and McCabe, S. (1996). The Seven Deadly Sins of Statistical Analysis, Annals of Plastic Surgery, Vol. 37, No. 3, pp. 265-272.

Larson, L.M., Rottinghaus, P.J. and Borgen, F.H. (2002). Meta-Analyses of Big Six Interests and Big Five Personality Factors, Journal of Vocational Behavior, Vol. 61, No. 2, pp. 217-239.

Lewis, M. (1989). Liar's Poker: Rising through the Wreckage of Wall Street, New York, NY: Hodder and Stoughton.

Lichten, C. (2013). Gender Equality to Play Part in Funding Decisions under Horizon 2020, Research Europe, No. 369, 18 July.

Lockwood, P. (2006). 'Someone Like Me Can Be Successful': Do College Students Need SameGender Role Models?, Psychology of Women Quarterly, Vol. 30, No. 1, pp. 36-46.

Long, C. (2009). The Scared Mile, Sunday Times, 18 October 2009.

Lynn, C. (2005). Leg the Spread: A Woman's Adventures Inside the Trillion-Dollar Boys' Club of Commodities Trading, Chichester: Capstone Publishing.

Maddock, S. and Parkin, D. (1993). Gender Cultures: How They Affect Men and Women at Work, Women in Management Review, Vol. 8, No. 2, pp. 3-9.

McDowell, L. (1997). Capital Culture: Gender at Work in the City, Oxford: Wiley-Blackwell.

McDowell, L. (2010). Capital Culture Revisited: Sex, Testosterone and the City, International Journal of Urban and Regional Research, Vol. 34, No. 3, pp. 652-658.

Mello, Z.R. (2008). Gender Variation in Developmental Trajectories of Educational and Occupational Expectations and Attainment from Adolescence to Adulthood, Developmental Psychology, Vol. 44, No. 4, pp. 1069-1080.

Merchant, K. (2012). How Men and Women Differ: Gender Differences in Communication Styles, Influence Tactics and Leadership Styles, CMC Senior Thesis, Paper 513, Claremont Colleges [online], available from: <http://scholarship.claremont.edu/cmc_theses/513>, accessed 11 March 2015.

Morgan, S.L., Gelbgiser, D. and Weeden, K.A. (2013).Feeding the Pipeline: Gender, Occupational Plans, and College Major Selection, Social Science Research, Vol. 42, No. 4, pp. 989-1005.

Moya, E. (2011). Glass Ceiling Is Thicker in Investment Banking than in Other Areas of Finance, Financial News [online], 29 March, available from: <http:/ / www.efinancialnews. com/story/2011-03-28/glass-ceiling-is-thicker-in-investment-banking-than-in-otherareas-of-finance>, accessed 11 March 2015.

North-Samardzic, A. and Taksa, L. (2011). The Impact of Gender Culture on Women's Career Trajectories: An Australian Case Study, Equality, Diversity and Inclusion: An International Journal, Vol. 30, No. 3, pp. 196-216.

Ogden, S.M., McTavish, D. and McKean, L. (2006). Clearing the Way for Gender Balance in the Management of the UK Financial Services Industry: Enablers and Barriers, Women in Management Review, Vol. 21, No. 1, pp. 40-53.

Ozbilgin, M.F. and Woodward, D. (2004). 'Belonging' and 'Otherness': Sex Equality in Banking in Turkey and Britain, Gender, Work E Organization, Vol. 11, No. 6, pp. 668-688.

Parkin, F. (1974). The Social Analysis of Class Structure, London: Routledge. 
Poggio, B. (2000). Between Bytes and Bricks: Gender Cultures in Work Contexts, Economic and Industrial Democracy, Vol. 21, No. 3, pp. 381-402.

PricewaterhouseCoopers (2013). Mending the Gender Gap - Advancing Tomorrow's Women Leaders in Financial Services [online], May 2013, available from: <http:/ / www.pwc.com/ en_US/us/financial-services/publications/assets/pwc-advancing-women-in-financialservices.pdf $>$, accessed 22 February 2015.

Pryce, P and Sealy, R. (2013). Promoting Women to MD in Investment Banking: Multi-Level Influences, Gender in Management, an International Journal, Vol. 28, No 8, pp. 448-467.

Rees, T. (2005). Reflections on the Uneven Development of Gender Mainstreaming in Europe, International Feminist Journal of Politics, Vol. 7, No. 4, pp. 555-574.

Rhoton, L.A. (2011). Distancing as a Gendered Barrier Understanding Women Scientists' Gender Practices, Gender \& Society, Vol. 25, No. 6, pp. 696-716.

Riach, K. and Cutcher, L. (2014). Built to Last: Ageing, Class and the Masculine Body in a UK Hedge Fund, Work, Employment and Society, Vol. 28, No.5, pp. 771-787.

Rosenbloom, J.L., Ash, R.A., Dupont, B. and Coder, L.A. (2008). Why Are there so Few Women in Information Technology? Assessing the Role of Personality in Career Choices, Journal of Economic Psychology, Vol. 29, No. 4, pp. 543-554.

Rosenthal, R. (1991). Meta-Analytic Procedures for Social Research, revised edition, Newbury Park, CA; London: Sage Publications.

Roth, L.M. (2003). Selling Women Short: A Research Note on Gender Differences in Compensation on Wall Street, Social Forces, Vol. 82, No. 2, pp. 783-802.

Roth, L.M. (2006). Selling Women Short: Gender and Money on Wall Street, Princeton, NJ: Princeton University Press.

Rowe, T. and Crafford, A. (2003). A Study of Barriers to Career Advancement for Professional Women in Investment Banking, South African Journal of Human Resource Management, Vol. 1, No. 2, pp. 21-27.

Schoon, I. and Parsons, S. (2002). Teenage Aspirations for Future Careers and Occupational Outcomes, Journal of Vocational Behavior, Vol. 60, No. 2, pp. 262-288.

Sonnert, G. and Holton, G.J. (1995). Who Succeeds in Science? The Gender Dimension, New Brunswick, NJ: Rutgers University Press.

Suzana, S. (2009). Confessions of a City Girl, London: Virgin Books.

Tannen, D. (1990). You Just Don't Understand: Women and Men in Conversation, New York, NY: William Morrow.

Thompson, V. (2010). Gross Misconduct: My Year of Excess in the City, London: Pocket Books.

Turco, C.J. (2010). Cultural Foundations of Tokenism, American Sociological Review, Vol. 75, No. 6, pp. 894-913.

Twomey, A.M., Linehan, M. and Walsh, J.S. (2002). Career Progression of Young Female Accountants: Evidence from the Accountancy Profession in Ireland, Journal of European Industrial Training, Vol. 26, Nos. 2/3/4, pp. 117-124.

Valian, V. (2005). Beyond Gender Schemas: Improving the Advancement of Women in Academia, Hypatia, Vol. 20, No. 3, pp. 198-213.

Watt, H.M. (2010). Gender and Occupational Choice, in J.C. Chrisler and D.R. McCreary (eds), Handbook of Gender Research in Psychology, Volume 2: Gender Research in Social and Applied Psychology, New York, NY: Springer, pp. 379-400.

Weber, M. (1922). Economy and Society: An Outline of Interpretive Sociology, translated by G. Roth and G. Wittich, New York, NY: Bedminster.

Weisgram, E.S., Bigler, R.S. and Liben, L.S. (2010). Gender, Values, and Occupational Interests among Children, Adolescents, and Adults, Child Development, Vol. 81, No. 3, pp. 778-796.

Wigfield, A., Battle, A., Keller, L.B. and Eccles, J.S. (2002). Sex Differences in Motivation, SelfConcept, Career Aspiration, and Career Choice: Implications for Cognitive Development, 
Sheerin

in A.V. McGillicuddy-De Lisi and R. De Lisi (eds), Biology, Society, and Behavior: The Development of Sex Differences in Cognition, Greenwich, CT: Ablex, pp. 93-124.

Wilson, A.N. (2012). Yes, Women ARE Brighter. That's Why I'll Make a Prediction that Is Sure to Enrage Them, Daily Mail [online], 17 July, available from: <http:/ / www.dailymail. co.uk/debate/article-2174528/Yes-women-higher-IQ-men-thats-Ill-make-predictionenrage-them.html>, accessed 11 March 2015. 